ARTIKEL PENELITIAN

\title{
HUBUNGAN OBESITAS DENGAN PREEKLAMPSIA PADA IBU HAMIL TRIMESTER II DAN III
}

\author{
Rahmawati Wahyuni $^{1)}$, Azhari' ${ }^{2)}$, Nursari Abdul Syukur ${ }^{3)}$ \\ 1)3) Kebidanan, Prodi D-IV Kebidanan Samarinda, Politeknik Kesehatan \\ Kementerian Kesehatan Kalimantan Timur, Jl. Wolter Monginsidi No.38 \\ Samarinda Kode Pos 75123 \\ 2) Jurusan Analis Kesehatan Samarinda, Politeknik Kesehatan Kementerian \\ Kesehatan Kalimantan Timur, Jl. Kurnia Makmur No. 64 \\ E-mail: yunibid@gmail.com
}

\begin{abstract}
Maternal mortality rate in Indonesia is still high enough which is dominated by three main causes of death that is bleeding, preeclampsia, and infection. Maternal Mortality in Samarinda city in 2015 increased by 76 per 100,000 live births. Maternal mortality in Samarinda city, dominated maternal death aged 20-34 years that fall into maternal and maternal death category. One of the causes of maternal death is preeclampsia and one of the causes of preeclampsia in pregnant women is obesity. The purpose of this study to determine the relationship of obesity with preeclampsia in pregnant women trimester II and III in RSUD Abdul Wahab Sjahranie Samarinda with specified $\alpha$ is 0,05 The design of this study is cross sectional, sampling technique with purposive sampling of 39 pregnant women trimester II and III. The results of this study found there is a significant relationship between obesity with preeclampsia in pregnant women trimester II and III ( $p$ value = 0.006 ) with the value of $\alpha=0.05$. There is a significant relationship between obesity with preeclampsia in pregnant women trimester II and III in RSUD Abdul Wahab Sjahranie Samarinda 2018.
\end{abstract}

Keywords : Obesity, Preeclampsia, Pregnant Women trimester II and III

\begin{abstract}
Abstrak
Angka kematian ibu di Indonesia masih cukup tinggi yang didominasi oleh tiga penyebab utama kematian yaitu perdarahan, preeklampsia, dan infeksi. Kematian ibu di kota Samarinda tahun 2015 meningkat menjadi 76 per 100.000 kelahiran hidup hidup. AKI di kota samarinda, didominasi kematian ibu usia 20-34 tahun yang masuk dalam kategori kematian ibu hamil dan ibu bersalin. Salah satu penyebab kematian ibu adalah preeklampsia dan salah satu penyebab terjadinya preeklampsia pada ibu hamil yaitu obesitas. Tujuan penelitian ini untuk mengetahui hubungan obesitas dengan preeklampsia pada ibu hamil trimester II dan III di RSUD Abdul Wahab Sjahranie Samarinda dengan $\alpha$ yang ditentukan adalah 0,05Desain penelitian ini adalah cross sectional, Teknik pengambilan sampel dengan purposive sampling dan responden sebanyak 39 ibu hamil trimester II dan III. Hasil penelitian ini diperoleh terdapat hubungan bermakna antara obesitas dengan preeklampsia pada ibu hamil trimester II dan III ( $p$ value $=0,006)$ dengan nilai $\alpha=0,05$. Terdapat hubungan bermakna antara obesitas dengan preeklampsia pada ibu hamil trimester II dan III di RSUD Abdul Wahab Sjahranie Samarinda Tahun 2018.

Kata Kunci : Obesitas, preeklampsia, wanita hamil trimester II dan III
\end{abstract}

\section{PENDAHULUAN}

Menurut World Health

Organization (WHO), setiap tahun di

seluruh dunia $358.000 \mathrm{ibu}$ meninggal saat hamil atau bersalin di mana 355.000 ibu (99\%) berasal dari
negara berkembang. Dengan $75 \%$
Angka Kematian Ibu (AKI) akibat 
komplikasi selama hamil, bersalin dan $25 \%$ selama masa nifas. Hasil Survei Demografi Kesehatan Indonesia (SDKI) pada tahun 2012 menunjukkan peningkatan AKI yang signifikan yaitu menjadi 359 kematian ibu per 100.000 kelahiran hidup. (Sumarni,2014.)

AKI di Indonesia masih didominasi oleh tiga penyebab utama kematian yaitu perdarahan, hipertensi dalam kehamilan (HDK), dan infeksi. Namun proporsinya telah berubah, dimana perdarahan dan infeksi cenderung mengalami penurunan sedangkan HDK proporsinya semakin meningkat.(KemenkesRI,2015)

Menurut Dinas kesehatan Provinsi Kalimantan Timur (2015). AKI setiap tahun mengalami penurunan pada tahun 2013 sebesar 113 kasus kematian, turun pada tahun 2014 menjadi 104 kasus dan 2015 menjadi 100 kasus kematian ibu.

AKI di kota Samarinda tahun 2015 sebesar 76 per 100.000 kelahiran hidup yang menunjukkan peningkatan jumlah AKI pada tahun 2014 yakni 50 per 100.000 kelahiran hidup. AKI tahun 2015 didominasi kematian ibu usia 20-34 tahun yang masuk dalam kategori kematian ibu hamil dan ibu bersalin. Salah satu penyebab kematian ibu adalah preeklampsia.

Preeklampsia merupakan penyakit yang ditandai dengan adanya peningkatan tekanan darah diatas 140/90 $\mathrm{mmHg}$ dan proteinuria dan edema yang timbul pada kehamilan setelah minggu ke-20 atau sampai 48 jam postpartum (Maryunani, dkk, 2012; Dinkes Kaltim, 2015) Ibu hamil dengan preeklampsia di RSUD Abdul Wahab Sjahranie Samarinda sebanyak 94 ibu hamil dari $1370 \mathrm{ibu}$ hamil pada bulan januari sampai Oktober 2017. (Diklit RSUD AWS, 2017).

Penyebab terjadinya preeklampsia sampai saat ini belum diketahui, tetapi beberapa penelitian menyimpulkan sejumlah faktor yang mempengaruhi terjadinya preeklampsia salah satunya yaitu kegemukan/obesitas selama kehamilan (Kurnia, 2013).

Obesitas kehamilan adalah kenaikan berat badan pada ibu hamil melebihi 12-16 $\mathrm{kg}$ berat badan 
normal dan berdampak buruk bagi kesehatan terutama pada ibu hamil, dimana dapat menyebabkan hipertensi, hiperkolesterol, hiperglikemia yang dikenal dengan $(3 \mathrm{H})$. Wanita hamil dengan obesitas akan memerlukan perawatan yang lebih jika dibandingkan wanita hamil dengan berat badan normal, obesitas berisiko tinggi menimbulkan hipertensi dalam kehamilan, abortus, bayi makrosomia, fase persalinan yang lambat, distosia bahu, persalinan dengan seksio sesaria (Sanjaya, 2015). Penelitian yang dilakukan oleh James et al menyatakan bahwa berat badan berlebihan pada wanita hamil berhubungan dengan preeklampsia (Dumais,2016)

\section{METODE PENELITIAN}

Penelitian ini merupakan penelitian kuantitatif jenis penelitian yang digunakan Analitik dengan pendekatan cross sectional Pengambilan sampel pada penelitian ini dilakukan secara non probability sampling yaitu Purposive Sampling.
Variabel independent dalam penelitian ini adalah obesitas dan variabel Dependent adalah preeklampsia. Populasi dalam penelitian ini sebanyak 94 ibu hamil. Pengambilan sampel pada penelitian ini dilakukan secara non probability sampling yaitu Purposive Sampling dengan menggunakan rumus proporsi sampel dan sampel yang didapatkan yaitu sebanyak 39 responden. Dengan kriteria inklusi : a) Ibu hamil Trimester II dan III. b) Ibu hamil dengan preeklampsia trimester II dan III. c).Ibu hamil dengan obesitas trimester II dan III. d). Ibu hamil preeklampsia dengan obesitas trimester II dan III. Kriteria eksklusi : a) Ibu hamil gemelli. b). Ibu hamil dengan diabetes. Pelaksaan analisis menggunakan komputer. Analisis univariat digunakan untuk mendapatkan gambaran distribusi responden dan analisis bivariat dengan uji chi-square.

\section{HASIL DAN PEMBAHASAN}

1. Karakteristik Responden 
Berdasarkan tabel diatas pada karakteristik umur menunjukkan bahwa sebagian besar responden umur 20-35 tahun sebanyak 22 responden $\quad(56,4 \%) \cdot P a d a$ karakteristik pekerjaan menunjukkan bahwa hampir seluruhnya responden sebagai ibu rumah tangga sebanyak 28 responden (71,8\%). Pada karakteristik paritas menunjukkan bahwa hampir seluruhnya responden multigravida sebanyak 30 responden $(76,9 \%)$. Pada karakteristik riwayat hipertensi menunjukkan bahwa sebagian besar responden tidak memiliki riwayat hipertensi sebanyak 26

Tabel 4. 1

Distribusi Frekuensi Karakteristik Ibu Hamil Trimester II dan III

\begin{tabular}{lcc}
\hline Karakteristik & F & $\%$ \\
\hline Umur : & & \\
$<20$ & 2 & $5,1 \%$ \\
$20-35$ & 22 & $56,4 \%$ \\
$>35$ & 15 & $38,5 \%$ \\
\hline Pekerjaan : & & \\
IRT & 28 & $71,8 \%$ \\
Swasta & 10 & $25,6 \%$ \\
Bidan & 1 & $2,6 \%$ \\
\hline Paritas : & & \\
Primigravida & 9 & $23,1 \%$ \\
Multigravida & 30 & $76,9 \%$ \\
\hline Riwayat & & \\
Hipertesi & 13 & $33,3 \%$ \\
Ya & 26 & $66,6 \%$ \\
Tidak & & \\
\hline Total & 39 & 100,0 \\
& & $\%$ \\
\hline Sumber : Data & Primer, 2018
\end{tabular}

responden $(66,6)$.

\section{Analisis Univariat}

a. Obesitas

Tabel 4. 2

Distribusi Frekuensi

Kejadian Obesitas Pada

Ibu Hamil Trimester II

\begin{tabular}{ccc}
\multicolumn{3}{c}{ dan III } \\
\hline $\begin{array}{c}\text { Kejadian } \\
\text { Obesitas }\end{array}$ & F & $\%$ \\
\hline Obesitas & 2 & 64,1 \\
& 5 & \\
Tidak & 1 & 35,9 \\
Obesitas & 4 & \\
\hline Total & 3 & 100,0
\end{tabular}

Sumber : Data Primer,

2018

Berdasarkan tabel diatas menunjukkan bahwa sebagian besar responden obesitas sebanyak 25 responden (64, 1\%) dan sebagian kecil responden tidak obesitas sebanyak 14 responden $(35,9 \%)$.

b. Preeklampsia

Tabel 4.3

Distribusi Frekuensi

Kejadian Preeklampsia

Pada Ibu Hamil Trimester II dan III

$\begin{array}{ccc}\underset{\text { Kejadian }}{\text { Preeklampsi }} & \text { F } & \% \\ & & \end{array}$

\begin{tabular}{ccc}
$\mathbf{a}$ & & \\
\hline Preeklampsia & 25 & 64,1 \\
Tidak & 14 & 35,9 \\
Preeklampsia & & \\
\hline Total & 39 & $\begin{array}{c}100, \\
\end{array}$ \\
& & 0 \\
\hline
\end{tabular}


Sumber : Data Primer, 2018

Berdasarkan tabel diatas

menunjukkan bahwa sebagian

besar responden

preeklampsia sebanyak 25

responden $(64,1 \%)$ dan

sebagian kecil responden

tidak preeklampsia sebanyak

14 responden $(35,9 \%)$

\section{Hasil Analisis Bivariat}

Hasil uji chi-square dengan tingkat kepercyaan $95 \%(\alpha=0,05)$ menunjukkan bahwa $P=0,006$ $(P<0.05)$ maka $\mathrm{H}_{\mathrm{o}}$ ditolak. Dengan demikian menunjukan bahwa terdapat hubungan yang signifikan antara obesitas dengan preeklampsia pada ibu hamil trimester II dan III di RSUD Abdul Wahab Sjahranie

Tabel 4.4

Tabel Tabulasi Silang Obesitas dengan Preeklampsia Pada Ibu Hamil

\begin{tabular}{|c|c|c|c|c|c|c|c|c|}
\hline \multirow{3}{*}{$\begin{array}{c}\text { Ibu } \\
\text { Hamil }\end{array}$} & \multicolumn{4}{|c|}{ Preeklampsia } & \multirow{2}{*}{\multicolumn{2}{|c|}{ Total }} & \multirow{3}{*}{$\begin{array}{c}P \\
\text { Value }\end{array}$} & \multirow{3}{*}{$\mathbf{O R}$} \\
\hline & \multicolumn{2}{|c|}{ Preeklampsia } & \multicolumn{2}{|c|}{$\begin{array}{c}\text { Tidak } \\
\text { Preeklampsia }\end{array}$} & & & & \\
\hline & $\mathrm{F}$ & $\%$ & $\mathrm{~F}$ & $\%$ & $\mathrm{~F}$ & $\%$ & & \\
\hline Obesitas & 20 & 80 & 5 & 20 & 25 & 100 & & \\
\hline $\begin{array}{c}\text { Tidak } \\
\text { Obesitas }\end{array}$ & 5 & 35,7 & 9 & 64,3 & 14 & 100 & 0,006 & 7,200 \\
\hline Total & 25 & 64,1 & 14 & 35,9 & 29 & 100 & & \\
\hline
\end{tabular}

Sumber : Data Primer 2018

Berdasarkan tabel diatas menunjukkan bahwa hampir seluruh $(80 \%)$ responden obesitas dan preeklampsia. Sebagian besar $(64,3 \%)$ responden tidak obesitas dan tidak preeklampsia. hampir setengahnya $(35,7 \%)$ responden tidak obesitas namun preeklampsia. Sebagian kecil (20 $\%)$ responden obesitas namun tidak preeklampsia.
Samarinda. Berdasarkan analisis Odds Ratio (OR) diperoleh hasil 7,200 yang artinya ibu hamil yang mengalami obesitas 7,200 kali berpeluang mengalami preeklampsia.

Pembahasan

1. Hubungan Obesitas dengan Preeklampsia

Hasil penelitian menunjukkan bahwa hampir seluruh $(80 \%)$ 
responden obesitas dan preeklampsia. Sebagian besar $(64,3 \%)$ responden tidak obesitas dan tidak preeklampsia. Hampir setengahnya $(35,7 \%)$ responden tidak obesitas namun preeklampsia. Sebagian kecil (20\%) responden obesitas namun tidak preeklampsia. Hasil uji chisquare dengan tingkat kepercayaan $95 \%(\alpha=0,05)$ menunjukkan bahwa $P=0,006$ $(P<0.05)$ maka $\mathrm{H}_{\mathrm{o}}$ ditolak. Dengan demikian menunjukan bahwa terdapat hubungan obesitas dengan preeklampsia pada ibu hamil trimester II dan III di RSUD Abdul Wahab Sjahranie Samarinda. Hal ini sejalan dengan penelitian yang dilakukan oleh Cahyadi (2014) yang menyatakan bahwa terdapat hubungan obesitas dengan preeklampsia pada ibu hamil di RSUD Dr. Abdoerr Rahem Kabupaten Situbondo dengan $P$ value 0,014 .

Obesitas kehamilan merupakan kenaikan berat badan pada ibu hamil melebihi $12-16 \mathrm{~kg}$ berat badan normal dan akan mengalami masalah ketika persalinan dan pasca persalinan (Detiana,2010).

Obesitas terjadi jika ada ketidakseimbangan antara asupan makanan dengan aktivitas fisik.Regulasi utama terjadinya respon adaptasi tersebut adalah leptin yang merupakan derivate hormone adiposit, yang mana mempengaruhi otak terutama daerah hipotalamus terhadap nafsu makan, penggunaan energi, dan fungsi neuroendokrin (Flier, 2008).

Dalam hasil penelitian Wafiyatunisa (2016) menyatakan bahwa gaya hidup merupakan salah satu faktor terjadinya obesitas. Gaya hidup, diet dan aktivitas fisik berhubungan dengan terjadinya obesitas dan penyakit kardiovaskular. Risiko terjadinya preeklampsia pada wanita obesitas juga berhubungan dengan faktor gaya hidupnya. Hal ini berhubungan dengan karakteristik pekerjaan dalam penelitian ini dimana menunjukkan bahwa hampir seluruhnya responden sebagai ibu rumah tangga sebanyak 28 
responden $(71,8 \%)$. Penelitian ini didukung oleh penelitian Djannah (2010) yang menunjukkan bahwa kejadian preeklampsia lebih banyak diderita pada ibu yang tidak bekerja atau hanya sebagai ibu rumah tangga, hal ini dikarenakan aktivitas fisik lebih banyak dan stress yang merupakan faktor terjadinya preeklampsia.

Preeklampsia merupakan penyakit yang ditandai dengan adanya hipertensi dan proteinuria dan edema yang timbul pada kehamilan setelah minggu ke-20 atau sampai 48 jam postpartum (Maryunani,2012).

Dalam

Penelitian Serudji

menyatakan bahwa wanita dengan preeklampsia dapat ditemukan adanya lesi pada arteri uteroplasentalnya. Karakteristik lesinya adalah adanya daerah dengan nekrosis fibrinoid yang diliputi oleh sel makrofag yang memfagosit lipid. Lesi mikroskopis ini mirip dengan lesi yang ada pada atheroskeloris. Penumpukan lemak juga dapat ditemukan pada glomerulus dari pasien dengan preeklampsia dan biasa disebut glomerular endotheliosis. Adanya lesi pada glomerular ini berhubungan dengan terjadinya proteinuria. Lemak yang berlebihan juga dapat berperan dalam patofisiologi kerusakan endotel pada preeklampsia tingginya trigliserida akan meningkatkan risiko kelainan pembuluh darah plasenta yang akan merangsang terjadinya kelainan endotel, atherosceloris, dan thrombosis. Atherosclerosis pada wanita preeklampsia terjadi pada arteri spiralis pada plasenta. Wanita dengan peningkatan trigliserida memiliki risiko dua kali lipat mengalami preeklampsia dibandingkan dengan wanita dengan berat badan normal.

Dalam hasil penelitian Nafiisah (2016) Orang yang obesi tas, jantungnya bekerja lebih keras dalam memompa darah. Hal ini dapat dipahami karena biasanya pembuluh darah orang yang obesitas terjepit kulit yang berlemak, keadaan ini di duga dapat mengakibatkan naiknya 
tekanan darah. Orang yang obesitas tubuhnya bekerja lebih keras untuk membakar kelebihan kalori yang ada dalam tubuhnya, pembakaran kalori ini membutuhkan suplai oksigen dalam darah yang cukup, semakin banyak kalori yang dibakar, maka semakin banyak pula pasokan oksigen dalam darah, banyaknya pasokan darah tentu menjadikan jantung bekerja lebih keras, dan dampaknya pada orang obesitas tekanan darahnya cenderung lebih tinggi.

Hasil analisis dalam penelitian ini didapatkan nilai OR (Odds ratio) sebesar 7,200 yang berarti ibu hamil yang obesitas berisiko 7,200 kali untuk terkena preeklampsia. Penelitian ini sesuai dengan teori yang menyatakan bahwa obesitas disebabkan oleh banyak faktor seperti konsumsi makanan yang berlebihan, maka makin gemuk seseorang makin banyak pula jumlah darah yang terdapat didalam tubuh yang berarti makin berat pula fungsi jantung dalam memompa darah, sehingga dapat menyebabkan preeklampsia.

Berdasarkan karakteristik dalam Penelitian ini ibu yang mengalami preeklampsia dominan terjadi pada responden yang berusia 20-35 tahun sebanyak 22 responden $(56,4 \%)$, responden multigravida $(76,9 \%), \quad$ dan responden yang tidak memiliki riwayat hipertensi $(66,6 \%)$. Ibu hamil dengan usia $<20$ tahun akan cenderung mengalami preeklampsia hal ini dikarenakan kurangnya maturitas organ reproduksi serta tidak melakukan pemeriksaan kehamilan secara teratur.

Ibu Hamil dengan usia 20-35 tahun merupakan umur yang paling aman untuk hamil sebab pada usia tersebut fungsi alat reproduksi cukup optimal untuk hamil maupun melahirkan. Ibu hamil dengan usia > 35 tahun kemungkinan terjadinya komplikasi dalam kehamilan meningkat dikarekanan fungsi organ reproduksi yang mulai menurun (Magdalena, 2013). Hasil penelitian ini juga didukung 
oleh penelitian Wahyunani (2015) yang menyatakan bahwa tidak ada hubungan yang signifikan antara umur dengan kejadian preeklampsia.

Pada penelitian ini ibu yang mengalami preeklampsia lebih banyak terjadi pada ibu hamil multigravida daripada ibu hamil primigravida. Hal ini dukung dalam hasil penelitian yang dilakukan oleh Sutrimah (2015) yang menyatakan bahwa tidak terdapat hubungan antara paritas dengan kejadian preeklampsia pada ibu hamil.

Pada karakteristik riwayat hipertensi ibu hamil yang megalami preeklampsia sebagian besar responden tidak memiliki riwayat hipertensi $(66,6 \%)$. Hal ini bertolak belakang dengan hasil penelitian Magdalena (2013) disebutkan bahwa Salah satu faktor terjadinya preeklampsia adalah adanya riwayat hipertensi kronis, atau penyakit vaskuler hipertensi sebelumnya, atau hipertensi esensial.

Peneliti berasumsi bahwa ibu hamil yang obesitas atau lemak yang berlebihan didalam tubuh dapat menyebabkan tekanan darah meningkat sehingga terjadi preeklampsia pada ibu hamil hal ini dikarenakan fungsi jantung yang semakin berat dalam memompa darah sehingga ibu hamil yang obesitas cenderung mengalami preeklampsia. Dalam penelitian ini Ibu yang tidak bekerja lebih cenderung mengalami obesitas dikarenakan aktivitas fisik yang kurang dan meningkatnya nafsu makan.

Dalam penelitian ini ibu hamil yang mengalami preeklampsia terjadi pada rentang usia usia 20-35 tahun dan multigravida hal ini pula dikarenakan proses kehamilan dan persalinan umunya terjadi pada usia produktif 20-35 tahun sehingga preeklampsia lebih banyak terjadi pada multigravida.

Sebagian besar ibu hamil yang preeklampsia tidak memiliki riwayat hipertensi sebelumnya hal ini menunjukkan bahwa kejadian preeklampsia bukan hanya disebabkan oleh faktor riwayat hipertensi saja, melainkan 
terdapat faktor lain yang mempengaruhi dan saling berkaitan dalam memberikan resiko terhadap kejadian preeklampsia.

\section{c. Keterbatasan Penelitian}

1. Peneliti hanya melakukan penelitian dalam waktu yang singkat

2. Peneliti tidak meneliti faktorfator lain yang mempengaruhi preeklampsia seperti riwayat penyakit hipertensi pada keluarga, kehamilan ganda, jarak kehamilan.

\section{SIMPULAN}

Berdasarkan hasil penelitian dan pembahasan, maka dapat disimpulkan :

1. Gambaran ibu hamil trimester II dan III yang mengalami Obesitas di RSUD Abdul Wahab Sjahranie Samarinda Tahun 2018 sebanyak $64,1 \%$

2. Gambaran ibu hamil trimester II dan III yang mengalami Preeklampsia di RSUD Abdul Wahab Sjahranie Samarinda Tahun 2018 sebanyak 64,1\%
3. Gambaran ibu hamil trimester II dan III yang mengalami Obesitas dan Preeklampsia di RSUD Abdul Wahab Sjahranie Samarinda sebanyak $80 \%$

4. Terdapat hubungan yang signifikan antara obesitas dengan preeklampsia pada ibu hamil trimester II dan III di RSUD Abdul Wahab Sjahranie Samarinda dilihat dari nilai $P$ value $0.006<\alpha 0.05$.

\section{Saran}

1. Bagi peneliti diharapkan dapat memperbanyak pengetahuan dan informasi tentang obesitas dalam kehamilan dan preeklampsia sehingga dapat memberikan informasi langsung kepada masyarakat

2. Ibu hamil hendaknya menjaga berat badan dan rutin memeriksakan kehamilannya setiap bulan untuk mengontrol tekanan darah dan berat badan selama hamil

3. Bagi tenaga kesehatan khususnya bidan menyampaikan informasi/ penyuluhan kepada ibu hamil mengenai nutrisi pada ibu hamil 
agar ibu hamil memahami gizi yang baik dan aman bagi ibu hamil dan meminimalisir kejadian obesitas pada ibu hamil yang berdampak pada kejadian preeklampsia.

\section{DAFTAR PUSTAKA}

Djannah, S. nur dan ika sukma., 2010. Gambaran Epidemiologi Kejadian

Preeklampsia/Ekslampsia di RSUPKU Muhammadiyah Yogyakarta.

Dyaanggari, S., 2015. Luaran Maternal dan Perinatal Pada Ibu Hamil dengan Preeklampsia Berat.

Detiana., 2010. Hamil Aman Dan Nyaman Diatas Usia 30 tahun, yogyakarta: PT. buku sata.

Flier, J. . (2008). Biology of Obesity. Harrison's Priciples of Internal Medicine.

Kementrian Kesehatan RI, Keputusan Direktur Jenderal Bina Upaya Kesehatan Nomor HK.02.03/II/1911/2013 Tentang Pedoman Penyelenggaraan Magdalena, M., 2013. Gambaran Faktor Penyebab Preeklampsia
Pada Kehamilan Di Wilayah Kerja Puskesmas Tembelang Jombang. Diakses dari http://jurnalbidan.stikespemkabjo mbang.ac.id/index.php/maret201 6/article/view/30/29

Maryunani, A. dkk., 2012. Asuhan Kegawatdaruratan Dalam Kebidanan, Jakarta: Trans Info Medika.

Nafiisah., 2016. Hubungan Antara Obesitas Dengan Preeklampsia Di RSUD Ambarawa.

Notoatmodjo, S., 2010. Metodologi Penelitian Kesehatan, Jakarta: Rineka Cipta.

Nur, A., 2012. Hubungan Lingkar Lengan Atas (LILA) Ibu Hamil dengan Angka Kejadian Preeklampsia Di RS. PKU Muhammadiyah surakarta. Retrieved from https://ejournal.unsrat.ac.id/index .php/ebiomedik/article/view/4363 Prawirohardjo, S., 2010. Ilmu Kebidanan, Jakarta: Yayasan Bina Pustaka.

Serudji, J., 2014. Perbandingan Kejadian Kehamilan Preeklampsia Berdasarkan Komponen Metabolik . Diakses 
Mahakam Midwifery Journal, Vol 2, No. 5, Mei 2019 : 312-323

darihttp://jurnalobgin.fk.unand.ac.

22 September 2017.

id/index.php/JOE/article/view/22. 